Article

\title{
Supported Photocatalyst for Removal of Emerging Contaminants from Wastewater in a Continuous Packed-Bed Photoreactor Configuration
}

\author{
$M^{\mathrm{a}}$ Emma Borges ${ }^{1}$, Dulce María García ${ }^{1}$, Tania Hernández ${ }^{1}$, Juan Carlos Ruiz-Morales ${ }^{2}$ and \\ Pedro Esparza $2, *$
}

1 Chemical Engineering Department, University of La Laguna, Avda. Astrofísico Fco. Sánchez s/n, La Laguna, Tenerife, Canary Island 38200, Spain; E-Mails: eborges@ull.es (M.E.B.); alumniuniv2@gmail.com (D.M.G.); alumniuniv1@gmail.com (T.H.)

2 Inorganic Chemistry Department, University of La Laguna, Avda. Astrofísico Fco. Sánchez s/n, La Laguna, Tenerife, Canary Island 38200, Spain; E-Mail: jcruiz@ull.es

* Author to whom correspondence should be addressed; E-Mail: pesparza@ull.es; Tel.: +34-922-318-006, Fax: +34-922-318-003.

Academic Editor: Keith Hohn

Received: 4 November 2014 / Accepted: 15 January 2015 / Published: 2 February 2015

\begin{abstract}
Water pollution from emerging contaminants (ECs) or emerging pollutants is an important environmental problem. Heterogeneous photocatalytic treatment, as advanced oxidation treatment of wastewater effluents, has been proposed to solve this problem. In this paper, a heterogeneous photocatalytic process was studied for emergent contaminants removal using paracetamol as a model contaminant molecule. $\mathrm{TiO}_{2}$ photocatalytic activity was evaluated using two photocatalytic reactor configurations: Photocatalyst solid suspension in wastewater in a stirred photoreactor and $\mathrm{TiO}_{2}$ supported on glass spheres (TGS) configuring a packed bed photoreactor. The surface morphology and texture of the TGS were monitored by scanning electron microscope (SEM). The influence of photocatalyst amount and wastewater $\mathrm{pH}$ were evaluated in the stirred photoreactor and the influence of wastewater flowrate was tested in the packed bed photoreactor, in order to obtain the optimal operation conditions. Moreover, results obtained were compared with those obtained from photolysis and adsorption studies, using the optimal operation conditions. Good photocatalytic activities have been observed and leads to the conclusion that the heterogeneous photocatalytic system in a packed bed is an effective method for removal of emerging pollutants.
\end{abstract}


Keywords: advanced oxidation technology (AOT); heterogeneous photocatalysis; emerging contaminants (ECs); endocrine disrupting chemicals (EDCs); paracetamol; $\mathrm{TiO}_{2}$; glass spheres

\section{Introduction}

In recent years, one of the most important aspects of environmental research has been the water pollution from emerging contaminants (ECs) such as endocrine disrupting chemicals (EDCs), pharmaceuticals and personal care products (PPCPs). Even they can be usually found in wastewater only at trace levels; their presence in aquatic environments raises the issue of their potential effects on human health and the environment [1-3]. Some adverse potential effects caused by ECs are aquatic toxicity, resistance development in pathogenic bacteria, genotoxicity and endocrine disruption [4-6].

Wastewater treatment plants are designed to remove conventional pollutants, such as suspended solids and biodegradable organic compounds, but they are not designed to remove low concentrations of synthetic pollutants, such as pharmaceuticals. These synthetic pollutants are resistant to conventional wastewater treatments. Advanced oxidation processes are treatments that are considered to be effective at removing EDCs from wastewater effluents. Advanced Oxidation Technology (AOT) has been examined to solve this environmental problem $[7,8]$.

AOT has provided innovative, highly cost-effective and catalyzed chemical oxidation processes for treatment of contaminated soil, sludge and wastewater. AOT can be broadly defined as aqueous phase oxidation methods based primarily on the intermediacy of hydroxyl radicals, $\mathrm{HO}^{\circ}$, in the mechanism leading to the destruction of the pollutant compounds [9-11]. The hydroxyl radical can be generated photochemically and it has high effectiveness for the oxidation of organic matter $[12,13]$.

Heterogeneous photocatalytic process is one of the most important AOTs and it is based on the oxidation of polluting compounds which can be found in air or water by means of a reaction occurring on a semiconductor catalytic surface activated by light with a specific wavelength.

$\mathrm{TiO}_{2}$ is the most investigated semiconductor catalyst particularly because it has great potential in solving environmental pollution [14] and it is chemically stable, non-toxic and inexpensive [15-17]. However, $\mathrm{TiO}_{2}$ has an important disadvantage because it is in powder form and, therefore, a post-treatment separation stage is needed for its use as photocatalytic material in wastewater decontamination by photocatalytic treatment $[18,19]$. This is the main reason why it is very useful to test the possibility of supporting the $\mathrm{TiO}_{2}$ active phase on several materials-e.g., activated carbon, silica, glass and polymers - in order for it to be used as photocatalysts in photocatalytic reactors for wastewater decontamination [20-22].

In this study, commercial $\mathrm{TiO}_{2}$ (Degussa P25) supported on glass spheres was evaluated as photocatalyst in a packed bed photo reactor used to remove emergent contaminants in wastewater. Paracetamol has been used as emergent contaminant model molecule, which is a common analgesic and antipyretic drug, and it is heavily used all over the world and can be found in effluent of wastewater treatment plants [23]. 


\section{Results and Discussion}

$\mathrm{TiO}_{2}$ active phase was analyzed by XRD and its crystalline phases were obtained. Table 1 shows the percentage of anatase and rutile phase, observing that $\mathrm{TiO}_{2}$ Degussa P25 is composed mainly by the photocatalitically active anatase phase [24,25]. In addition, Table 1 presents the textural parameters of $\mathrm{TiO}_{2}$ Degussa P25, which were examined by $\mathrm{N}_{2}$ adsorption-desorption porosimetry and mercury porosimetry. The textural parameters included in this table are: BET specific area $(A \mathrm{BET})$, total pore area $(A)$, porosity $(\varepsilon)$ and density $(\rho)$.

Table 1. $\mathrm{TiO}_{2}$ Degussa P25 characterization.

\begin{tabular}{ccccccc}
\hline \multicolumn{2}{c}{ XRD } & \multicolumn{1}{c}{$\mathrm{N}_{2}$ adsorption } & \multicolumn{3}{c}{ Hg porosimetry } \\
\hline \% Anatase & \% Rutile & $\left.\boldsymbol{A}_{\text {BET }}\left(\mathbf{m}^{2} / \mathbf{g}\right)\right)$ & $\boldsymbol{A}\left(\mathbf{m}^{2} / \mathbf{g}\right)$ & $\boldsymbol{\varepsilon}(\boldsymbol{\%})$ & $\boldsymbol{\rho}_{\text {bulk }}(\mathbf{g} / \mathbf{m L})$ & $\boldsymbol{\rho}_{\text {apparent }}(\mathbf{g} / \mathbf{m L})$ \\
\hline 81 & 19 & 51.1 & 63.7 & 92.46 & 0.19 & 2.58 \\
\hline
\end{tabular}

Prior to the study of the photocatalytic process, experiments in the stirred photoreactor have been performed in order to quantify the photolytic effect of the UV light on the paracetamol degradation in wastewater $(\mathrm{pH}=8)$ and the adsorption of the emergent contaminant molecules onto the $\mathrm{TiO}_{2}$ surface. Figure 1 shows the degree of paracetamol removal from wastewater by means of both phenomenon in the photoreactor: Photolysis or adsorption. It can be concluded that the photolytic process has relatively low effect in the paracetamol removal from wastewater under UV light irradiation.

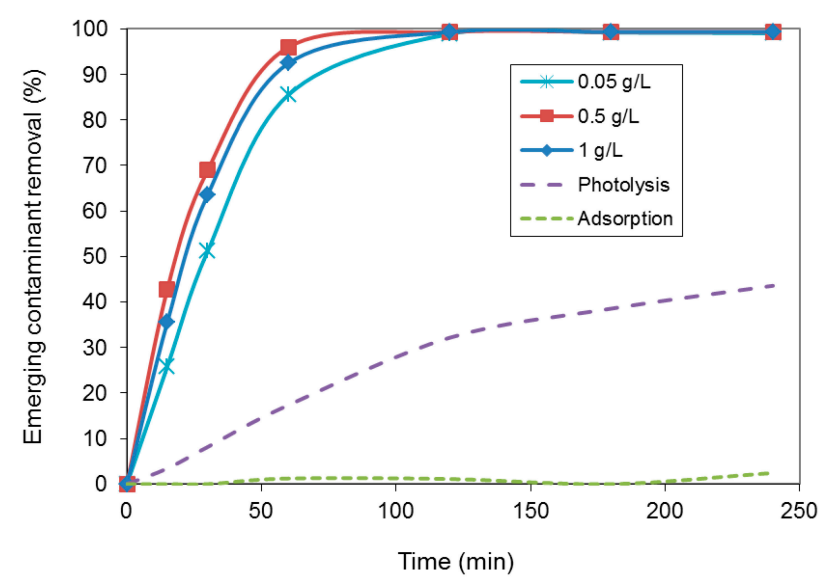

Figure 1. Paracetamol removal in the stirred batch photoreactor using $\mathrm{TiO}_{2}$ suspension as photocatalyst.

The adsorption capacity of the studied photocatalytic material, $\mathrm{TiO}_{2}$ Degussa $\mathrm{P} 25$, can be observed in Figure 1, evaluating its degree of contribution in the global process of elimination of the contaminant. As can be seen, the adsorption capacity of tested material is negligible (achieving only a $2 \%-3 \%$ of paracetamol removal from wastewater after $4 \mathrm{~h}$ of adsorption treatment) for all tested $\mathrm{TiO}_{2}$ quantities.

The activity of $\mathrm{TiO}_{2}$ photocatalytically active phase was studied in the stirred photoreactor configuration and the influence of the photocatalyst amount in the photoreactor has been presented in Figure 1. It can be seen that the paracetamol removal reaches an approximately constant value after $2 \mathrm{~h}$ of photocatalytic treatment for all the quantities of photocatalyst tested achieving values in the range $99 \%-100 \%$ of contaminant removal after $4 \mathrm{~h}$ of irradiation time. Therefore, these results from 
photocatalytic decontamination process can be compared with those results obtained from previous paracetamol photolysis and paracetamol adsorption studies, confirming that the paracetamol removal is mainly due to the heterogeneous photocatalytic treatment. This fact indicates that this kind of emergent contaminants in water can be degraded and mineralized by photocatalytic treatment with $\mathrm{TiO}_{2}$ as photocatalyst, achieving a total elimination of contaminants from wastewater.

Moreover, the results show that the optimal photocatalyst amount is $0.50 \mathrm{~g} / \mathrm{L}$, knowing that further increases in the photocatalyst amount used do not increase the photocatalytic ability of the system. This is because when the photocatalyst amount suspended in wastewater is increased, the light path is obstructed in the water due to its turbidity increases causing an "shade" effect and, therefore, HO" radical formation [26] and the effectiveness of the photocatalytic process induced by light is reduced.

Furthermore, a kinetic study of paracetamol degradation in water by photocatalysis was developed finding that the paracetamol degradation curves exhibit a mono-exponential trend, suggesting that a pseudo-first order reaction model can be applied to describe the kinetic behaviour [6,23,24,27-29] obtained from the $\mathrm{TiO}_{2}$ active phase acting as photocatalyst in the heterogeneous photocatalytic treatment. Pseudo-first order kinetics with respect to paracetamol concentration $(C)$ may be expressed as:

$$
-\frac{d C}{d t}=k_{a p p} C
$$

Integration of this equation leads to following equation:

$$
\ln \left(C_{0} / C\right)=k_{a p p} \cdot t
$$

where $k_{\text {app }}$ is the apparent pseudo-first order rate constant, $C_{0}$ is the initial paracetamol concentration and $\mathrm{t}$ is the photocatalytic reaction time or irradiation time. The values of $k$ app were obtained directly from the regression analysis of the plot of $\ln \left(C_{0} / C\right) v s$. photodegradation time for all experiments. Thus, Table 2 shows the $k_{\text {app }}$ values obtained for all tested amounts of $\mathrm{TiO}_{2}$ Degussa P25 acting as photocatalyst.

Table 2. Apparent kinetic parameters for paracetamol photodegradation.

\begin{tabular}{cc}
\hline Photocatalyst amount $(\mathrm{g} / \mathbf{L})$ & $\boldsymbol{k}_{\text {app }}\left(\mathbf{m i n}^{-\mathbf{1}}\right)$ \\
\hline 0.05 & 0.036 \\
0.10 & 0.040 \\
0.25 & 0.038 \\
0.50 & 0.045 \\
1.00 & 0.042 \\
\hline
\end{tabular}

The $\mathrm{pH}$ influence in the paracetamol photodegradation was examined in the stirred photoreactor using the optimal photocatalyst amount $\left(0.50 \mathrm{~g} / \mathrm{L}\right.$ of $\mathrm{TiO}_{2}$ Degussa $\left.\mathrm{P} 25\right)$ obtained from the previous kinetic study. As can be seen in the results presented in Figure 2, $\mathrm{pH}$ can also influence the contaminant degradation rate in the global photocatalytic process. The paracetamol removal curves show that the optimal $\mathrm{pH}$ is 8 and the degradation rate increases with increasing $\mathrm{pH}$ value. This can be attributed to enhanced formation of hydroxide ions, because at high $\mathrm{pH}$ more hydroxide ions available on $\mathrm{TiO}_{2}$ surface can be easily oxidized and form more hydroxide ions [30,31] which consequently increases the efficiency of paracetamol degradation. On the other hand, in Figure 2, the paracetamol removal decreased at pH 10 mainly due to surface ionization of $\mathrm{TiO}_{2}$. $\mathrm{TiO}_{2}$ surface is positively charged in acidic 
media and it is negatively charged at alkaline conditions. Increasing $\mathrm{pH}$ gradually increases the electrostatic repulsion between $\mathrm{TiO}_{2}$ surface and paracetamol [32] which is negatively charged at $\mathrm{pH}$ above 9.5, and the degradation rate of paracetamol is decreased at a $\mathrm{pH}$ higher than 9.5 [6].

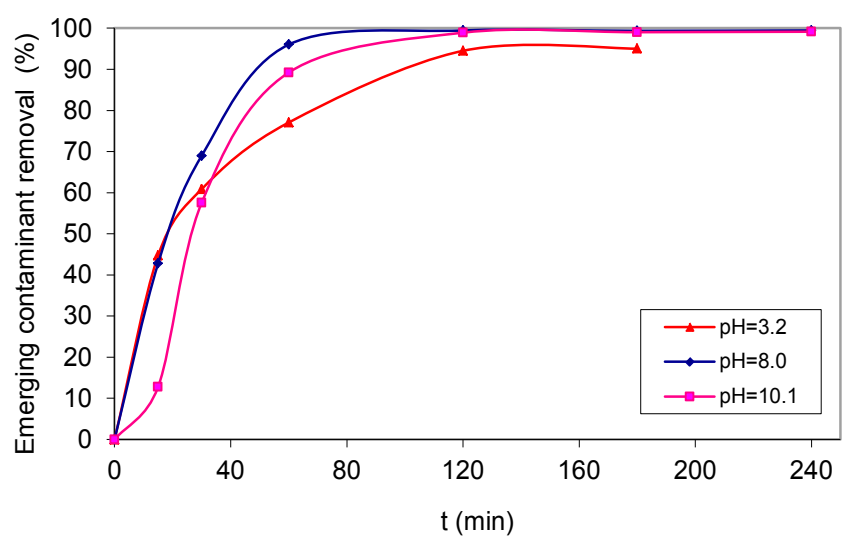

Figure 2. Influence of $\mathrm{pH}$ on the paracetamol removal by heterogeneous photocatalysis.

The surface morphology of the glass spheres, $\mathrm{TiO}_{2}$ supported on glass spheres (TGS) and TGS, after being used for photocatalytic experiments were revealed by SEM. The SEM images (Figure 3) show that glass spheres that were $\mathrm{TiO}_{2}$ supported (TGS) exhibit a similar morphology before and after photocatalytic experiments, consequently, demonstrating that the procedure's deposit of $\mathrm{TiO}_{2}$ active phase over glass spheres is efficient, and a stable support was achieved.
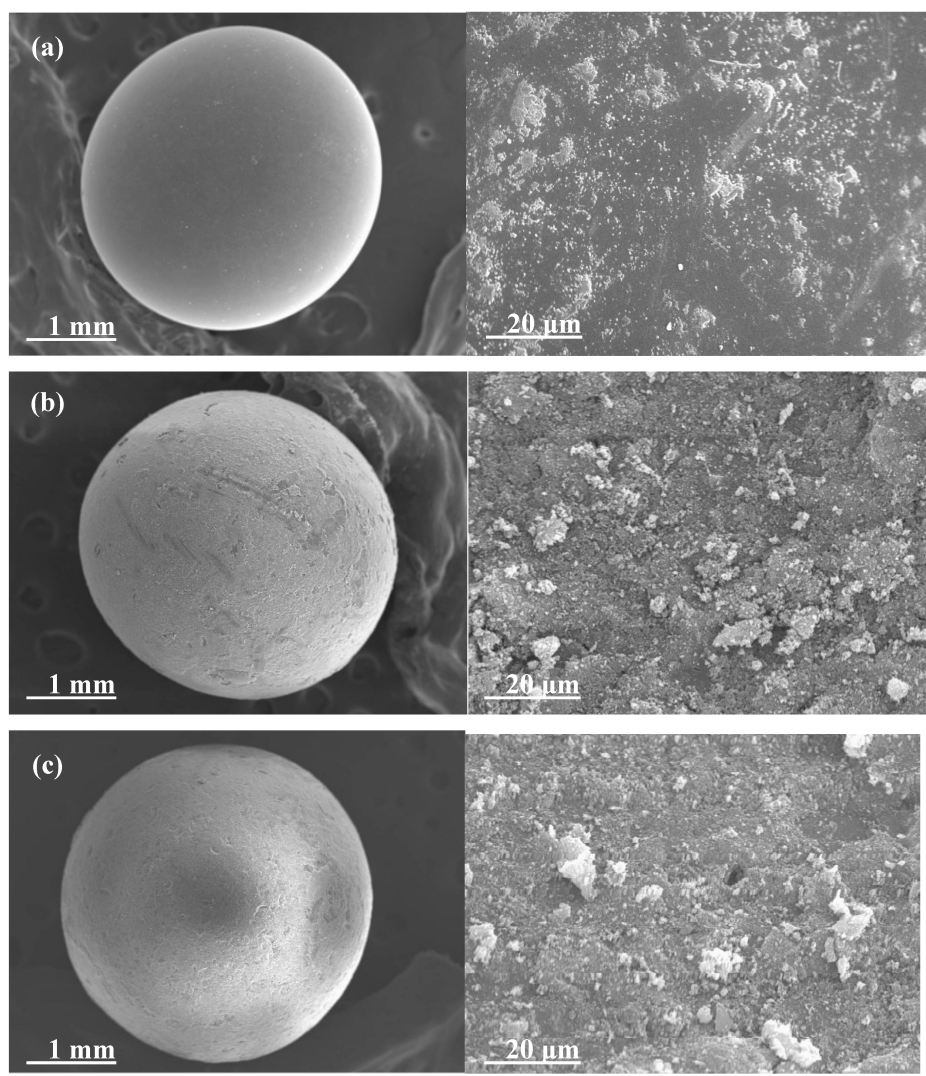

Figure 3. SEM images: (a) Glass sphere; (b) $\mathrm{TiO}_{2}$ supported on glass spheres (TGS); (c) TGS after photocatalytic experiments. 
The paracetamol photodegradation with TGS acting as photocatalyst in the packed-bed photoreactor was evaluated studying first the influence of the wastewater flowrate along the packed-bed photoreactor on the degree of contaminant removal (Figure 4). The photolytic effect of the irradiation light used and the photocatalytic material adsorption capacity related to the global paracetamol removal was evaluated in this reactor configuration using the optimal flowrate in order to determinate the degree of contribution of both phenomenon in the global decontamination process.

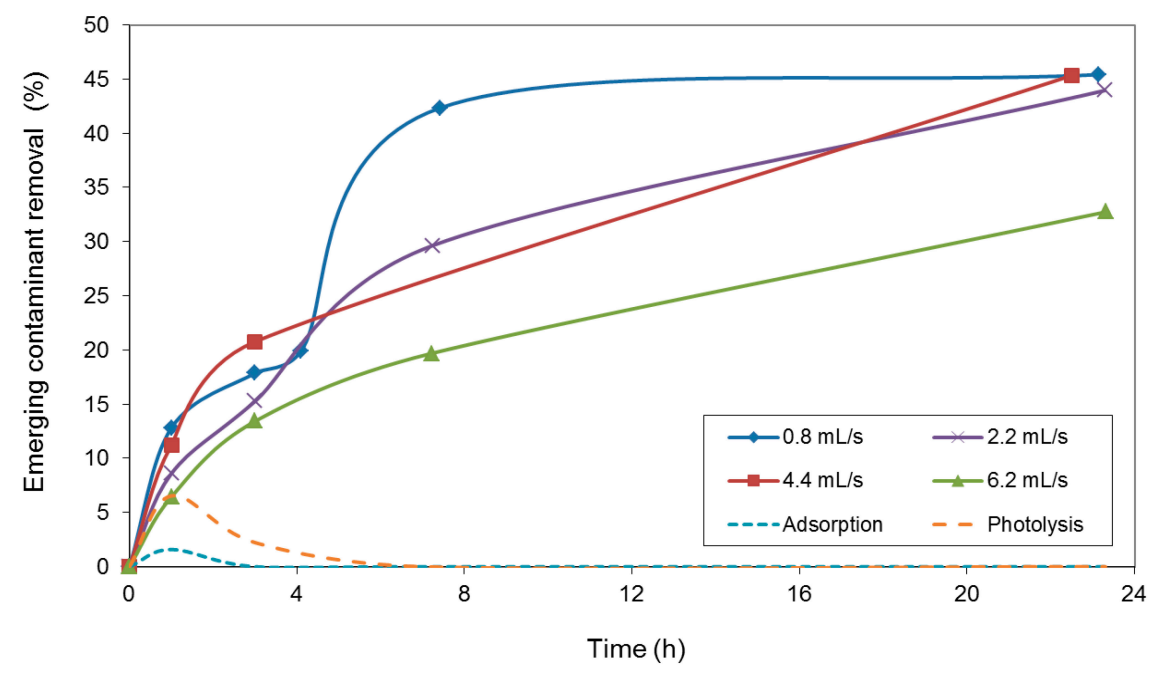

Figure 4. Emerging paracetamol removal in the fixed-bed photoreactor system.

As can be seen, the optimal photocatalytic activity was achieved using the lower flowrate along the packed-bed photoreactor $(0.8 \mathrm{~mL} / \mathrm{s})$, reaching a constant value of paracetamol removal (approximately $42 \%$ ) after $8 \mathrm{~h}$ of photocatalytic treatment. Meanwhile, the global paracetamol removal decreases for higher wastewater recirculation flowrates. In addition, the paracetamol removal shows an important increase after $4 \mathrm{~h}$ of photocatalytic treatment when $0.8 \mathrm{~mL} / \mathrm{s}$ was used as wastewater flowrate, following a pattern similar to those observed in a photocatalytic process for the removal of a mixture of pharmaceuticals from wastewater [33]. These results can be explained by an increased oxidation rate of some intermediates in the photocatalytic process.

Additionally, from photolysis and adsorption studies, carried out with the optimal flowrate $(0.8 \mathrm{~mL} / \mathrm{s})$, negligible paracetamol removal was observed after $23 \mathrm{~h}$ of treatment. This fact confirms that the paracetamol removal is only due to the heterogeneous photocatalytic treatment in the packed bed photoreactor.

\section{Experimental Section}

In this paper, the activity of $\mathrm{TiO}_{2}$ supported over glass spheres (TGS) as photocatalyst was studied evaluating the paracetamol (Acofarma, Llobregat, Spain) (as emergent contaminant model molecule) removal from wastewater. This heterogeneously photocatalyzed decontamination process, using photocatalyst particles in a packed-bed photoreactor configuration (crafted in our laboratory team), was compared with those results obtained from experiments using a $\mathrm{TiO}_{2}$ active phase (Degussa $\mathrm{P} 25$, Frankfurt, Germany) suspension in wastewater in a conventional stirred photoreactor. 
The photocatalytically active material, $\mathrm{TiO}_{2}$ Degussa (Frankfurt, Germany) P25, was examined by X-ray diffraction (XRD) in order to obtain the percentage of anatase and rutile phase. Nitrogen adsorption-desorption porosimetry and mercury porosimetry techniques were used to study its specific surface area and textural properties.

Glass spheres, in the range 2-3 mm diameter, were used as support material in order to configure a packed-bed reactor with $\mathrm{TiO}_{2}$ catalytically active phase. Before coating, the glass spheres were etched for $24 \mathrm{~h}$ in diluted hydrofluoric acid, washed thoroughly with deionized water and dried at $105{ }^{\circ} \mathrm{C}$ for $2 \mathrm{~h}$. Titanium (IV) isopropoxide (Aldrich, Steinheim, Germany) and ethanol were mixed with HCl. A hydroxide sol was obtained by hydrolysis of titanium (IV) isopropoxide. The surface modified glass spheres were immersed for $10 \mathrm{~min}$ in the hydroxide sol. Finally, glass spheres were dipped into suspension for 10 min and, after coating, they were dried at $105{ }^{\circ} \mathrm{C}$ and then calcinated at $450{ }^{\circ} \mathrm{C}$ for $2 \mathrm{~h}[34,35]$. The procedure was repeated until the spheres were coated with five layers obtaining $\mathrm{TiO}_{2}$ supported over glass spheres (TGS) studied as photocatalyst.

The surface morphology and texture of the glass spheres and TGS were monitored by means of scanning electron microscope (SEM).

The paracetamol photodegradation process with TGS as photocatalyst was conducted in a packed bed photoreactor system (Figure 5). TGS were placed in the photocatalytic reactor $(18 \mathrm{~cm}$ length, $0.6 \mathrm{~cm}$ internal diameter) and a solar radiation sodium vapour lamp (Philips, Amsterdam, Netherland, model 400-W G/92/2), placed at a distance of $50 \mathrm{~cm}$ from the packed-bed reactor, was used as light source (total radiation flux measured on the packed-bed surface was $160 \mathrm{~mW} / \mathrm{cm}^{2}$ ). Paracetamol solution in water $(50 \mathrm{mg} / \mathrm{L})$ was introduced in the wastewater tank $(250 \mathrm{~mL})$, photoreactor temperature was kept constant at $20{ }^{\circ} \mathrm{C}$ and the paracetamol solution was recirculated along the system using a peristaltic pump; several samples were taken during $23 \mathrm{~h}$ of irradiation time and they were analysed by UV-Vis spectrophotometry determining the absorbance of paracetamol at $\lambda=244 \mathrm{~nm}$, in order to study the degradation of paracetamol as contaminant in wastewater. The optimal wastewater recirculation flowrate was studied. Moreover, paracetamol photolysis (with light source and without photocatalyst) and paracetamol adsorption onto TGS (with photocatalyst and without light source) experiments were developed in order to evaluate its contribution to the emergent contaminant degradation or global wastewater decontamination process.

The study of the photocatalytic degradation of paracetamol with $\mathrm{TiO}_{2}$ active phase as photocatalyst suspension in wastewater was carried out in a stirred photoreactor $(800 \mathrm{~mL})$ using a UV radiation mercury lamp (Heraeus, Hanau, Germany, model TQ-150, $150 \mathrm{~W}$ ) as light source. UV system is placed positioned coaxial inside reaction vessel (total radiation flux measured on the stirred photoreactor was $120 \mathrm{~mW} / \mathrm{cm}^{2}$ ). In this photoreactor the temperature was kept constant at $20^{\circ} \mathrm{C}$, the paracetamol solution $(50 \mathrm{mg} / \mathrm{L})$ and the photocatalytic active phase in powder form $\left(\mathrm{TiO}_{2}\right.$ Degussa $\left.\mathrm{P} 25\right)$ were introduced into the photoreactor and several samples were taken during $4 \mathrm{~h}$ of irradiation time and then analysed by UV-Vis spectrophotometry in order to follow the evolution of paracetamol concentration into the reactor. The optimal amount of photocatalyst and the $\mathrm{pH}$ influence were evaluated in this experimental system, pH was adjusted by using $\mathrm{NaOH}(0.1 \mathrm{M})$ or $\mathrm{HCl}(0.1 \mathrm{M})$. Additionally, paracetamol photolysis and adsorption phenomenon in this reactor configuration were evaluated. 


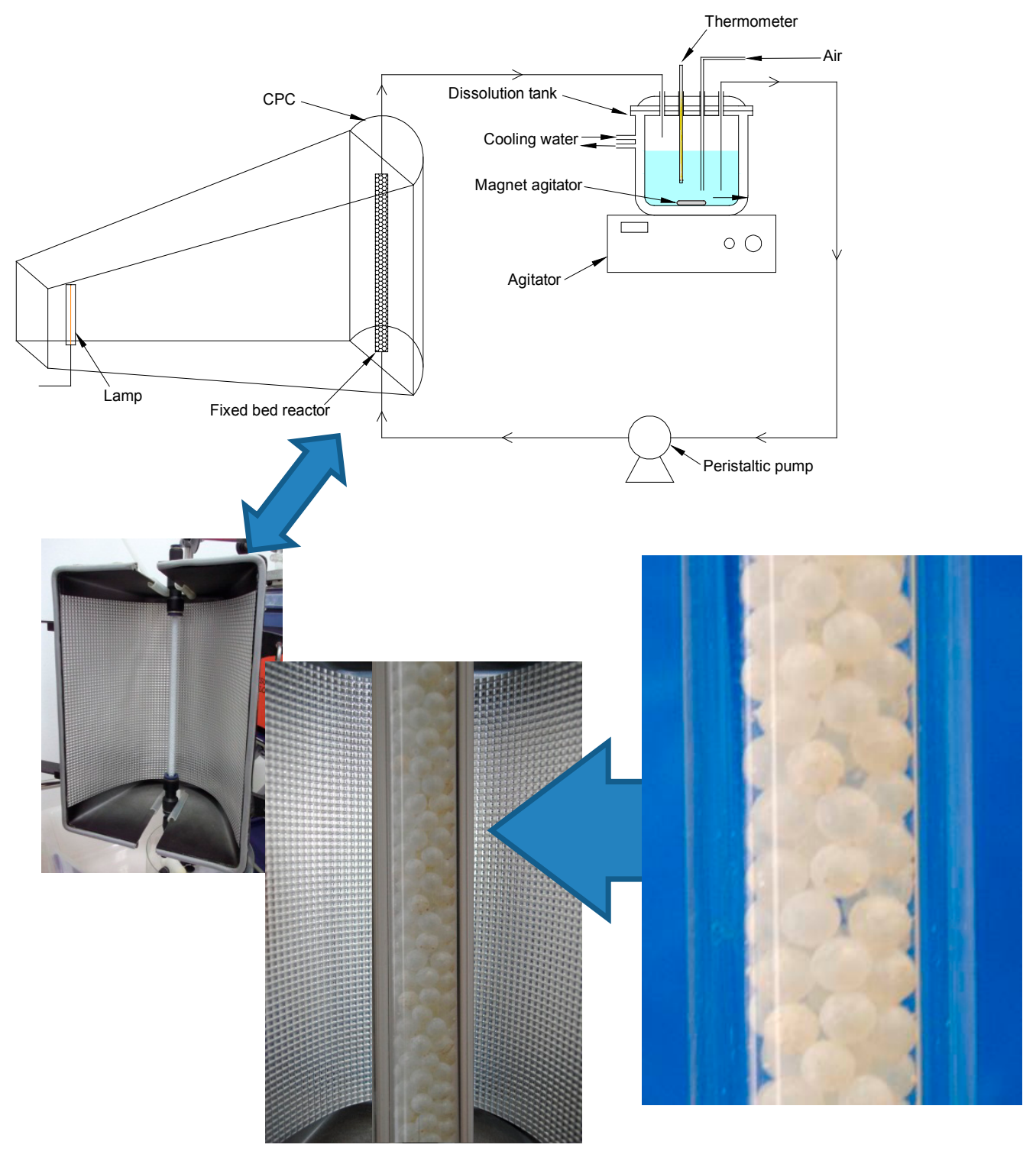

Figure 5. Packed-bed photoreactor system and glass spheres photocatalytic bed in photoreactor.

\section{Conclusions}

The study of the stirred photoreactor reveals that $\mathrm{TiO}_{2}$ Degussa P25 shows a good photocatalytic activity for the paracetamol removal from wastewater, reaching a high photodegradation (between 99\% and $100 \%$ of paracetamol removal after $4 \mathrm{~h}$ of irradiation) for all the amounts of photocatalyst tested.

It was concluded that the paracetamol degradation reaction by photocatalysis can be modeled by a pseudo-first-order kinetic equation and the optimal photocatalyst amount is $0.5 \mathrm{~g} / \mathrm{L}$ obtaining a high photodegradation rate using the photocatalyst in suspension in wastewater. Photocatalytic activity is improved when water in the $\mathrm{pH}$ range of conventional domestic wastewater is treated.

Photocatalytic treatment in batch systems using the photocatalyst suspension in water shows disadvantages for treating high volumes of domestic or industrial wastewater, requiring a subsequent treatment after photodegradation of contaminants in order to separate the photocatalyst $\left(\mathrm{TiO}_{2}\right.$ in powder form) from the treated water effluent. 
A photocatalytic decontamination process using the photocatalytic active phase supported in glass spheres configuring a packed-bed system with continuous recirculating wastewater flow has been implemented. Good photodecomposition of the emergent contaminant has been achieved - approximately $42 \%$ of paracetamol removal from wastewater after $8 \mathrm{~h}$ of photocatalytic treatment in the photocatalytic packed-bed continuous system. This continuous system shows clear advantages from an industrial treatment of wastewater point of view. Photocatalytic materials remain confined to the packed-bed, and no separation step is necessary for obtaining decontaminated water effluent.

\section{Acknowledgments}

This research was partially supported by the project FOTOCAT of "Fundación Cajacanarias" and by Spanish Ministry of Economy and Competitiveness (Project ENE2013-47826-C4-1R). Authors thanks the kind collaboration of Jorge Méndez-Ramos (Physics Department, University of La Laguna).

\section{Author Contributions}

All authors were involved in the conception and design of the experiments, as well as the collection, analysis and interpretation of data and writing or editing of this manuscript. All authors approved the final version of the manuscript.

\section{Conflicts of Interest}

The authors declare no conflict of interest.

\section{References}

1. Hernando, M.D.; Mezcua, M.; Fernández-Alba, A.R.; Barceló, D. Environmental risk assessment of pharmaceutical residues in wastewater effluents, surface waters and sediments. Talanta 2006, 69, 334-342.

2. Miranda-García, N.; Suárez, S.; Sánchez, B.; Coronado, J.M.; Malato, S.; Maldonado, M.I. Photocatalytic degradation of emerging contaminants in municipal wastewater treatment plant effluents using immobilized $\mathrm{TiO}_{2}$ in a solar pilot plant. Appl. Catal. B 2011, 103, 294-301.

3. Zhang, Z.; Hibberd, A.; Zhou, J.L. Analysis of emerging contaminants in sewage effluent and river water: Comparison between spot and passive sampling. Anal. Chimi. Acta 2008, 607, 37-44.

4. Miranda-García, N.; Maldonado, M.I.; Coronado, J.M.; Malato, S. Degradation study of 15 emerging contaminants at low concentration by immobilized $\mathrm{TiO}_{2}$ in a pilot plant. Catal. Today 2010, 151, 107-113.

5. Schriks, M.; Heringa, M.B.; van der Kooi, M.M.E.; de Voogt, P.; van Wezel, A.P. Toxicological relevance of emerging contaminants for drinking water quality. Water Res. 2010, 44, 461-476.

6. Yang, L.; Yu, L.E.; Madhumita, M.B. Degradation of paracetamol in aqueous solutions by $\mathrm{TiO}_{2}$ photocatalysis. Water Res. 2008, 42, 3480-3488. 
7. Pelaez, M.; Nolan, N.T.; Pillai, S.C.; Seery, M.K.; Falaras, P.; Kontos, A.G.; Dunlop, P.S.M.; Hamilton, J.W.J.; Byrne, J.A.; O’Shea, K.; et al. A review on the visible light active titanium dioxide photocatalysts for environmental applications. Appl. Catal. B 2012, 125, 331-349.

8. Sousa, M.A.; Gonçalves, C.; Vilar, V.J.P.; Boaventura, R.A.R.; Alpendurada, M.F. Suspended $\mathrm{TiO}_{2}$-assisted photocatalytic degradation of emerging contaminants in a municipal WWTP effluent using a solar pilot plant with CPCs. Chem. Eng. J. 2012, 198-199, 301-309.

9. Litter, M.I.; Quici, N. Photochemical advanced oxidation processes for water and wastewater treatment. Recent Pat. Eng. 2010, 4, 217-241.

10. Lydakis-Simantiris, A.; Riga, D.; Katsivela, E.; Mantzavinos, D.; Xekoukoulotakis, N.P. Disinfection of spring water and secondary treated municipal wastewater by $\mathrm{TiO}_{2}$ photocatalysis. Desalination 2010, 250, 351-355.

11. Robert, D.; Malato, S. Solar photocatalysis: A clean process for water detoxification. Sci. Total Environ. 2001, 291, 85-97.

12. Kositzi, M.; Poulios, I.; Malato, S.; Caceres, J.; Campos, A. Solar photocatalytic treatment of synthetic municipal wastewater. Water Res. 2004, 38, 1147-1154.

13. Wu, R.J.; Chen, C.C.; Lu, C.S.; Hsu, P.Y.; Chen, M.H. Phorate degradation by $\mathrm{TiO}_{2}$ photocatalysis: Parameter and reaction pathway investigations. Desalination 2010, 250, 869-875.

14. Wei, Y.-L.; Chen, K.-W.; Wang, H.P. Study of Chromium Modified $\mathrm{TiO}_{2}$ Nano Catalyst under Visible Light Irradiation. J. Nanosci. Nanotechnol. 2010, 10, 1-5.

15. Bahadur, N.; Jain, K.; Srivastava, A.K.; Govind; Gakhar, R.; Haranath, D.; Dulat, M.S. Effect of nominal doping of $\mathrm{Ag}$ and $\mathrm{Ni}$ on the crystalline structure and photo-catalytic properties of mesoporous titania. Mater. Chem. Phys. 2010, 124, 600-608.

16. Peng, Y.-H.; Huang, G.-F.; Huang, W.-Q. Visible-light absorption and photocatalytic activity of Cr-doped $\mathrm{TiO}_{2}$ nanocrystal films. Adv. Powder Technol. 2012, 23, 8-12.

17. Soutsas, K.; Karayannis, V.; Poulios, I.; Riga, A.; Ntampegliotis, K.; Spiliotis, X.; Papapolymerou, G. Decolorization and degradation of reactive azo dyes via heterogeneous photocatalytic processes. Desalination 2010, 250, 345-350.

18. Li, Y.; Chen, J.; Liu, J.; Ma, M.; Chen, W.; Li, L. Activated carbon supported $\mathrm{TiO}_{2}$-photocatalysis doped with $\mathrm{Fe}$ ions for continuous treatment of dye wastewater in a dynamic reactor. J. Environ. Sci. 2010, 22, 1290-1296.

19. Van Grieken, R.; Marugán, J.; Sordo, C.; Martínez, P.; Pablos, C. Photocatalytic inactivation of bacteria in water using suspended and immobilized silver-TiO2. Appl. Catal. B 2009, 93, 112-118.

20. Borges, M.E.; Alvarez-Galván, M.C.; Esparza, P.; Medina, E.; Martín-Zarza, P.; Fierro, J.L.G. Ti-containing volcanic ash as photocatalyst for degradation of phenol. Energy Environ. Sci. 2008, $1,364-369$.

21. Palau, J.; Colomer, M.; Penya-Roja, J.M.; Martínez-Soria, V. Photodegradation of Toluene, $m$-Xylene, and $n$-Butyl Acetate and Their Mixtures over $\mathrm{TiO}_{2}$ Catalyst on Glass Fibers. Ind. Eng. Chem. Res. 2012, 51, 5986-5994.

22. Song, M.Y.; Park, Y.-K.; Jurng, J. Direct coating of $\mathrm{V}_{2} \mathrm{O}_{5} / \mathrm{TiO}_{2}$ nanoparticles onto glass beads by chemical vapor deposition. Powder Technol. 2012, 231, 135-140.

23. Yang, L.; Yu, L.E.; Madhumita, M.B. Photocatalytic Oxidation of Paracetamol: Dominant Reactants, Intermediates, and Reaction Mechanisms. Environ. Sci. Technol. 2009, 43, 460-465. 
24. Janus, M.; Morawski, A.W. New method of improving photocatalytic activity of commercial Degussa P25 for azo dyes decomposition. Appl. Catal. B 2007, 75, 118-123.

25. Wong, C.L.; Tan, Y.N.; Mohamed, A.R. A review on the formation of titania nanotube photocatalysts by hydrothermal treatment. J. Environ. Manag. 2011, 92, 1669-1680.

26. Mangalampalli, V.; Sharma, P.; Sadanandam, G.; Ratnamala, A.; Kumari, V.D.; Subrahmanyam, M. An efficient and novel porous nanosilica supported $\mathrm{TiO}_{2}$ photocatalyst for pesticide degradation using solar light. J. Hazard. Mater. 2009, 171, 626-633.

27. Akbarzadeh, R.; Umbarkar, S.B.; Sonawane, R.S.; Takle, S.; Dongare, M.K. Vanadia-titania thin films for photocatalytic degradation of formaldehyde in sunlight. Appl. Catal. A 2010, 374, 103-109.

28. Dalrymple, O.K.; Yeh, D.H.; Trotz, M.A. Removing pharmaceuticals and endocrine-disrupting compounds from wastewater by photocatalysis. J. Chem. Technol. Biotechnol. 2007, 82, 121-134.

29. Dimitroula, H.; Daskalaki, V.M.; Frontistis, Z.; Kondarides, D.I.; Panagiotopoulou, P.; Xekoukoulotakis, N.P.; Mantzavinos, D. Solar photocatalysis for the abatement of emerging micro-contaminants in wastewater: Synthesis, characterization and testing of various $\mathrm{TiO}_{2}$ samples. Appl. Catal. B 2012, 117-118, 283-291.

30. Zheng, S.; Wang, Q.; Zhou, J.; Wang, B. A study on dye photoremoval on $\mathrm{TiO}_{2}$ suspension solution. J. Photochem. Photobiol. A 1997, 108, 235-238.

31. Galindo, C.; Jacques, P.; Kalt, A. Photodegradation of deaminobenzene acid orange 52 by three advanced oxidation process: $\mathrm{UV}-\mathrm{H}_{2} \mathrm{O}_{2}, \mathrm{Uv}-\mathrm{TiO}_{2}$ and $\mathrm{Vis}-\mathrm{TiO}_{2}$. Comparative mechanistic and kinetics investigation. J. Photochem. Photobiol. A 2000, 130, 35-47.

32. Brunner, M.; Schmiedberger, A.; Schmid, R.; Jager, D.; Piegler, E.; Eichler, H.; Muller, M. Direct assesment of peripheral pharmacokinetics in humans: Comparison between cantharides blister fluid sampling, in vivo microdialisys and saliva sampling. Br. Clin. Pharmacol. 1998, 46, 425-431.

33. Rizzo, L.; Meric, S.; Guida, M.; Kassinos, D.; Belgiorno, V. Heterogenous photocatalytic degradation kinetics and detoxification of an urban wastewater treatment plant effluent contaminated with pharmaceuticals. Water Res. 2009, 43, 4070-4078.

34. Hänel, A.; Morén, P.; Zaleska, A.; Hupka, J. Photocatalytic activity of $\mathrm{TiO}_{2}$ immobilized on glass beads. Physicochem. Probl. Miner. Process. 2010, 45, 49-56.

35. Kobayakawa, K.; Sato, C.; Sato, Y.; Fujishima, A. Continuous-flow photoreactor packed with titanium dioxide immobilized on large silica gel beads to decompose oxalic acid in excess water. J. Photochem. Photobiol. A 1998, 118, 65-69.

(C) 2015 by the authors; licensee MDPI, Basel, Switzerland. This article is an open access article distributed under the terms and conditions of the Creative Commons Attribution license (http://creativecommons.org/licenses/by/4.0/). 